\title{
STUDY OF MANAGEMENT OF EXTRACAPSULAR FRACTURE OF NECK OF FEMUR BY DYNAMIC HIP SCREW
}

G. Kishore Roy ${ }^{1}$, Muralidhar Bandi²

\section{HOW TO CITE THIS ARTICLE:}

G. Kishore Roy, Muralidhar Bandi."Study of Management of Extracapsular Fracture of Neck of Femur by Dynamic Hip Screw".Journal of Evolution of Medical and Dental Sciences 2014; Vol. 3, Issue 02, January 13; Page: 306-312, DOI:10.14260/jemds/2014/1826

\begin{abstract}
INTRODUCTION: Increased incidence of trochanteric fractures is a direct sequalae of ageing population. Treatment of trochantric fractures with internal fixation will have an added advantage of early mobilization and ambulation besides nursing care for fragile and supple individuals. The dynamic hip screw is one of the very simple, affordable device and surgically not a demanding procedure. The present study was undertaken to assess the utility of DHS as a useful method in the management of extracapsular fractures.MATERIALS AND METHODS: This is a prospective study undertaken to evaluate the effectiveness of dynamic hip screw fixation device in the management of extra capsular fracture neck of femur at ASRAM Medical College Hospital, Eluru during the periodbetween May 2008 and October 2010.Thirty patients with stable extracapsular fracture neck of femurtreated with dynamic hip screw fixation were selected for the present study.RESULTS: The final outcome was excellent in 16 patients, good in 10 patients, fair in 3 patients and poor in 1 patient.CONCLUSION: From this study we conclude that DHS is a good implant for the treatment of EVANS type -1 Extra capsular factures neck of femur. Because it enhances fracture stability and union with controlled collapse.
\end{abstract}

KEYWORDS:Extracapsular fractures of neck of femur, dynamic hip screw ABBREVATIONS: DHS-Dynamic hip screw

INTRODUCTION: Among the femoral bone injuries, trochanteric fractures present a relatively benign picture for management as they are not prone for difficult complications like non union and avascular necrosis but results in malunion (coxavara). Since the majority of people that suffer from extracapsular fractures are elderly, a special attempt is needed to avoid prolonged recumbency and thereby preventing associated complications. Before the introduction of internal fixation devices, treatment of inter trochanteric fractures were non operative, consisting ofbed rest and traction until fracture healing occurred(12-15 weeks) ${ }^{46}$, followed by a lengthy programme of ambulation and gait training. In elderly patients this is associated with complications like decubitus ulcers, urinary tract infection, joint contractures, pneumonia and thromboembolic phenomenonapart from varus deformity (coxavara) and shortening.For these reasons, treatment of intertrochanteric fractures by reduction and internal fixation has become the standard method of treatment world over.

Orthopaedic fraternity is always on the lookout for an effective and economical method of treatment for extracapsular fractures. The DYNAMIC HIP SCREW is one of the very simple, affordable device and surgically not a demanding procedure. The present study was undertaken to assess the utility of DHS as a useful method in the management of extracapsular fractures of hip.

MATERIALS AND METHODS:The present study is undertaken to evaluate the effectiveness of dynamic hip screw fixation device in the management of extra capsular fracture neck of femur at 
ASRAM MEDICAL COLLEGE HOSPITAL, Eluru during the periodbetween May 2008 and December 2010.Thirty patients with stable extracapsular fracture neck of femurtreated with DYNAMIC HIP SCREW fixation were selected for the present study.

Type 1 Evans classification type Inter trochanteric fractures in adults were selected for the present study. Type 2 Evans classification, compound fractures, pathological fractures, fractures in children and fractures in elderly patients with intractable osteoporosis were excluded from our study.

All the patients with extracapsular fractures neck of femur who were admitted to ASRAM Medical College Hospital were assessed clinically and were hemodynamically stabilized. Radiographs of pelvis with both hips (anteroposterior view) and full femur (anteroposterior view and lateral view) were taken. Skin traction was applied to the fractured limb and immobilized over a Bohler Braun frame till surgery. Basic surgical profile was done and fitness for anesthesia was obtained for all selected patients. Surgery was done over a fracture table in supine position under image intensifier(C-ARM) control using standard technique.

Drains were removed after 48 hours.Patients were assessed clinically and radiologically on the $2^{\text {ndpost }}$ operative day. Gentle mobilization of the operated limb, change of position and physiotherapy(quadriceps strengthening exercises, hip and knee bending exercises) were taught and the patients were discharged after 10-15 days.The patient was called after 6 weeks, 3 months, 6 months and finally afterone year. Patients were assessed for recovery and relief using HARRIS HIP SCORE.

RESULTS:Intraoperatively reduction was achieved through closed means in all patients. Reduction was good in 26 patients (87\%), acceptable in three out of 30 patients $(10 \%)$, poor in 1 patient $(3 \%)$ of patients.

Average time of fracture union for the present study was 5.04 months.

Final outcome was excellent in 16 patients, good in 10 patients, fair in 3 patients and poor in 1 patient in who cut-out of the screws from shaft of the femur occurred.

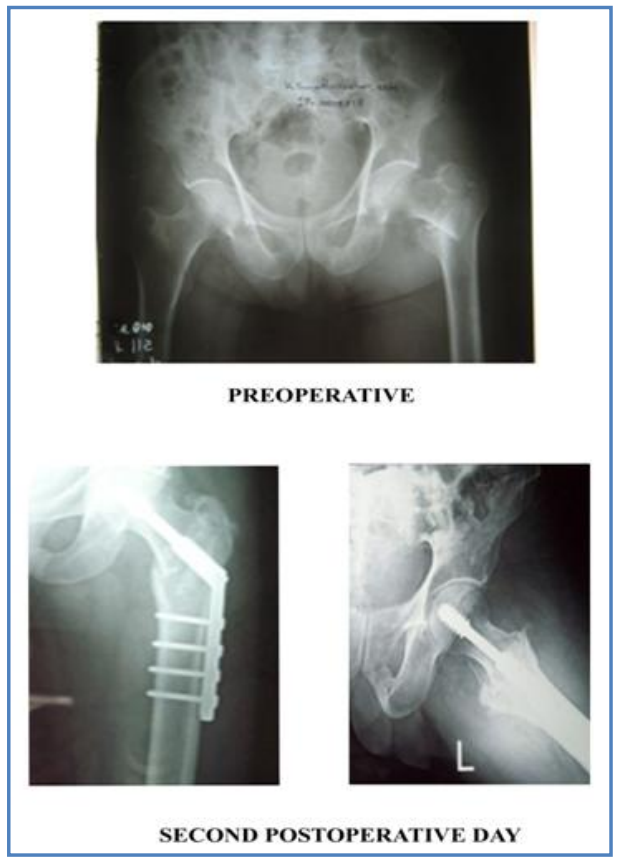




\section{REVIEW ARTICLE}
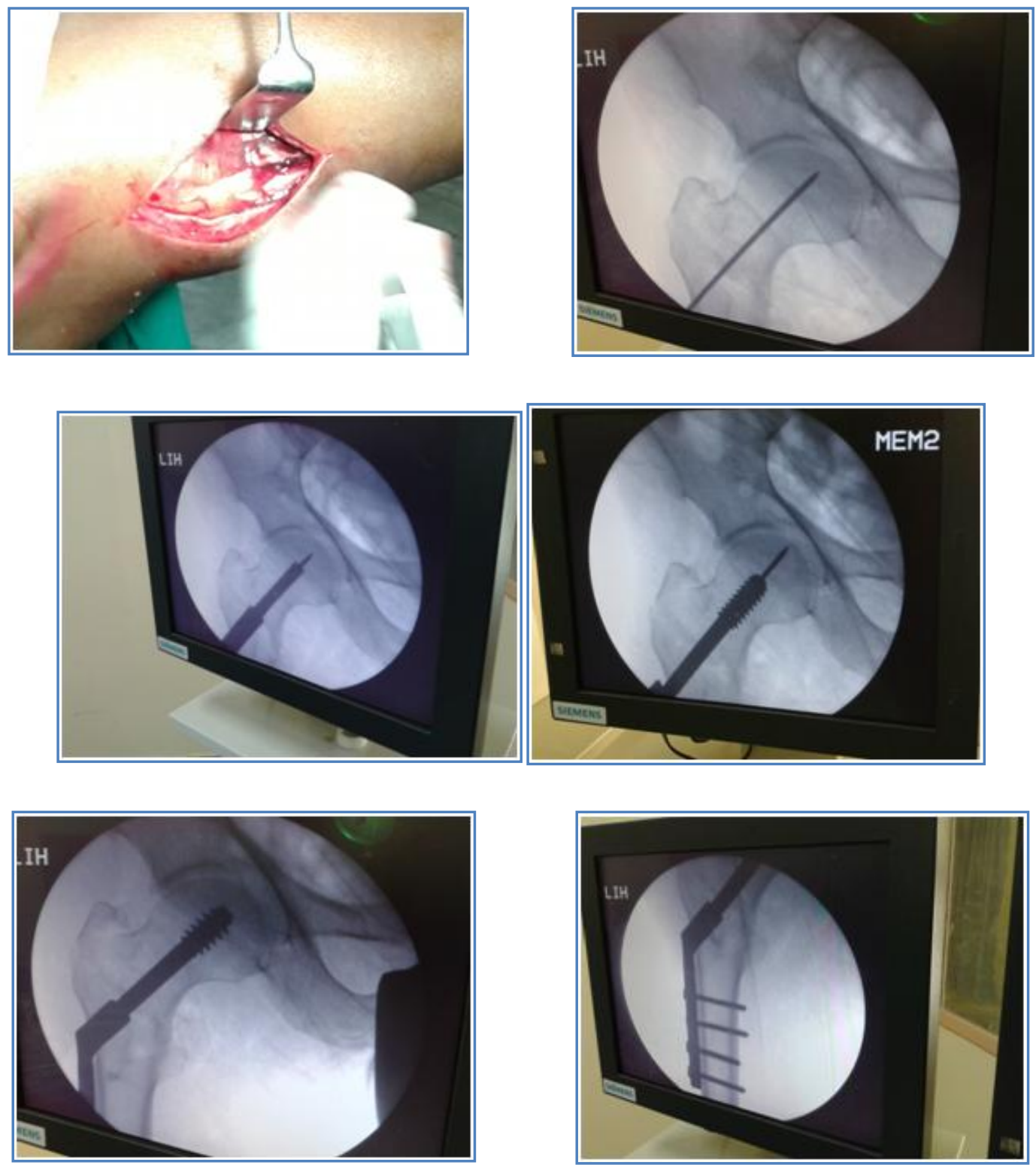

\section{Intraoperative pictures}

DISCUSSION: Intertrochanteric fractures are very common injuries seen in elderly. It is a major social and economic problem. The primary goal in the treatment is to reduce morbidity and avoid fracture complications. The dynamic hip screw has the mechanical advantage of static compression during surgery and dynamic compression after resumption of physiological loading. The benefit of continuous decrease in stress over the implant due to the sliding nature of the lag screw resulting in fracture union makes dynamic hip screw a good choice of implant for Evans type 1intertrochanteric fractures according to various clinical and radiological studies.

Most of the patients in the present study were in elderly age group(60 to 70 years). In our study 30 out of 42 patients (71.42\%), fractures involved the left femur. We had male preponderance of 28 out of 42 patients (66.66\%) as compared to ANIL KUMAR MISHRA SERIES 64.5\%,high female 
predominance was seen in KYLE ET AL SERIES 58\%, In30 out of 42 patients (71.42\%), fracture is a result of trivial fall. High velocity injuries such as fall from height, Road Traffic Accidentsinclude12 out of 42 patients (28.58\%). One patient had associated ipsilateral undisplaced tibia fracture which was treated conservatively.

In the present series the fractures were classified according to Evans classification. Out of 42 patients, subtype 1 includes 10 patients, subtype 2 includes 18 patients, subtype 3 includes 9 patients and subtype 4includes 5 patients. Admission operation interval in our study was 5.6 days as compared to 10 DAYS IN ANILMISHRA SERIES. It was 3 days in GULZAR AHMED SERIES.Dolk ${ }^{42}$ in his study found no difference in mortality and morbidity between those operated within 8 hours of admission and 48 hours of admission, indicating that there was no need to operate in extracapsular fractures neck of Femur as emergencies. Most of the patients with delayed injury operation interval had pre-existing difficult medical problems. Intra-operatively closed reduction was achieved in all the patients and the result was good in 36 out of 42 patients(85.7\%).Only one superficial infection $(2.3 \%)$ resulted after surgery which subsided with parenteral antibiotics. Coxa-vara was noted in 5 patients(11.9\%).Cut out of hip screw was noted in one patient, pullout of barrel plate from shaft was seen in one patient. The mean duration of hospital stay in our series was 19.26 days, which is same as found in N.CHIRODIAN SERIES(18.4DAYS), 2 TO 3 WEEKS IN GULZAR AHMED SERIES

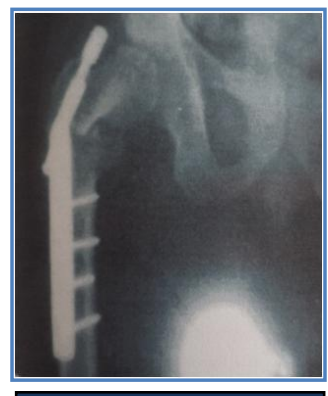

Screw cut-out

Average time for fracture union in our series is 14 weeks.(15 weeks in BOLHOFNER SERIES, 11.7 weeks in WOLFGANGSERIES ${ }^{41}, 14$ weeks in ECKERSERIES ${ }^{43}$ ). The fracture being entirely in the region of can cellous bone, we are of the view that the radiological union is deceptive to permit full weight-bearing. Hence, we feel that screw cutting through bone was seen in some occasions. Majority of the patients in this study 36 out of 42 patients $(85.7 \%)$ had no pain. moderate pain was present in 5 out of 42 patients (11.9\%) which was relieved by analgesics. Severe pain was present in only one person (N.CHIRODIAN SERIES 95\% (NONE 94.9\%, MODERATE 4.1\% AND SEVERE 1\% respectively).No shortening was seen in 34 out of 42 patients $(80.95 \%)$ more than $2 \mathrm{~cm}$ shortening was seen in 8 out of 42patients (19.05\%). Shortening was associated with limp. In 42 patients of our study 24 patients did not require any support for walking. 14 patients were using cane for long walks which mostly included geriatric patients. Hand cane was used most of the time in 3 patients and 1 patient could not walk. Squatting was possible in 36 out of 42 patients (85.7\%) but 6 patients had mild difficulty, 39 out of 42 patients(92.85\%) were able to sit cross legged but 3 patients had limitation of abduction and external rotation.

Final outcome was excellent in 26 patients, good in 12 patients, fair in 3 patients and poor in 1 patient in whom cut out of the screws from shaft of the femur occurred. 
GULZAR AHMED SERIES indicates (EXCELLENT to GOOD 96.5\%POOR 3.5\%)

CH.ARUN KUMAR SERIES 92\% EXCELLENT RESULTS

SUMMARY: From this study we conclude that DHS is a good implant for the treatment of EVANS type -1Extra capsular factures neck of femur. Because it enhances fracture stability and union with controlled collapse.

\section{BIBLIOGRAPHY:}

1. BrownJ.T.and AbramiG. Transcervicalfemoralfractures. JBJS1964;46B: 648-663.

2. BadgleyC.Treatment of displaced subcapital fractures of the femoral neck inaged with immediate replacement arthroplasty (Discussion). JBJS 1961;43B:606.

3. Falch JA, Liebekk A, Slungaard U. Epideomologyofhip fractures in Norway. ActaOrthopScand 1986;56: 12-16.

4. Wong PCN. Femoral neck fractures among the major racial groups in Singapore. Incidence pattern compared with non Asian communities. Singapore Med1984;J5:150-157cooper.

5. Cleveland M, Bosworth $M$, Thompson FR. Intertrochanteric fracture of femur, asurvey of treatment in traction and by internal fixation. J Bone Joint Surg 1947;29:1049-67aged with immediate replacement arthroplasty (Discussion). JBJS 1961;43B:606

6. KyleRichard F.: FacturesandDislocations, Chapter 23, GustiloRamonB., Kyle Richard F. and Templeman David (eds), Mosby, 1993, Vol. 2, 783-854.

7. Heyse-moore et al; Treatment of intertrochanteric fractures of femur JBJS 1983; 65-B; 262267.

8. Schumplik. W; Jansten OM; A aew principle in orthopaedic treatment of trochanteric fractures of femur JBJS July 1995, 37-4

9. Massie WK: Extracapsular fractures of hip treated by impaction using a sliding Nail-plate fixation. Clin Orthop1962; 180-202.)

10. JesseCDelee. RockwoodandGreen'sFracturesinAdults.Chapter 18, $3^{\text {rd }}$ edition 1991, Charles A. Rockwood, David P. Green and Robert W. BucholzJB (eds), Lippincott Company, Vol. 2, 14811651.

11. Jewett EL. One-Piece Angle Nail for Trochanteric Fractures. Journal of Boneand Joint Surgery 1941; 23: 803-810

12. SrivastvaKP. TextbookofOrthopaedicsandTrauma.KulakarniGS(eds), Jaypee Brothers Medical Publishers (P) Ltd., 1999, Vol.3, 2052-2072.

13. Clawson DK. Trochanteric fractures treated by the Sliding screw plate fixationmethod. J Trauma 1964; 4:737-756

14. Jensen JS, Tondevold E, HolmSS.Stabletrochantericfractures, a1cooper.Falch JA, Liebekk A, Slungaard U. Epideomologyofhip fractures in Norway.ActaOrthopScand 1986;56: 12-16

15. Comparative analysis of four methods of internal fixation. ActaOrthopScand 1980; 51: 811816

16. Jensen JS, Holm SS, Tondevold E. Unstable trochanteric fractures: A comparativeanalysis of four methods of internal fixation. ActaOrthopScand 1980; 51: 949- 962

17. JensenJS. Mechanical strength of Slidings crew platehipimplants, abiomechanical study of unstable intertrochanteric fractures. ActaOrthopScand1980; 51: 625-632 
18. Treatment of trochanteric fractures of the hip by modified Richards compressing and collapsing screw. G.S Kulkarni, Miraj, India, VOL. 18, No. 1, January 1984

19. The use of Ender's pin in extracapsular fractures of hip JBJS 1981;. 63; 14-28

20. Tracy Watson J. Comparison of the Compression Hip Screw with the MedoffSlidingPlateforIntertrochantericFractures;ClinicalOrthopaedicsandRelated Research 1998; 348: 79-86.

21. Dominique C. Hardy. Use of an Intramedullary Hip Screw Compared with aCompression Hip screw with a Plate for Intertrochanteric Femoral Fractures.Journal of Bone and Joint Surgery 1998; 80A: 618-630.

22. Baumgaertner MR, CurtinSL, Lindskog DM, Keggi JM. The Value of the Tip-Apex Distance in Predicting Failure of Fixation of PeritrochantericFracturesof the Hip. Journal of Bone and Joint Surgery 1995; 77A: 1058

23. Hardy et al; Use of an intramedullary hip screw compared with a compression hip screw with a plate for intertrochanteric femoral fractures JBJS 1998; 80-A;618-30

24. G nail.BridleSH, PatelAD, BircherM.Fixationofintertrochantericfracturesofthefemur, a randomised prospective comparison of the Gamma nail and the Dynamichip screw.J Bone Joint Surg1991; 73: 330-33493.Al-yassariG, LangstaffRJ, JonesJWM.

25. TheAO/ASIFproximalfemoralnail(PFN)forthetreatmentofunstabletrochantericfemoralfracture. Injury2002;33:395-399

26. 1991 British. Editorial. Society. ofBone and Joint. Surgery. 0301-620X/9l/6237New. Delhi. 1 10060, .IndiaA. DHAL, . M. VARGHESE, . V. B. BHASIN. THE JOURNAL.external fixation of inter trochanteric fractures.

27. KT Kamble Central Institute of Orthopaedics, Safdarjang Hospital, New Delhi, India...Safdarjang Hospital, New Delhi, India from June 1993 to January 1995.External fixation in intertrochanteric fractures of femur.

28. Reverse obliquity and transverse fractures of the trochanteric fractures of femur. Timothy et al, injury, int.j.care injured (2005)36, 851-857 concludes femoral medialization is better resisted by intra medullary implants for reverse oblique fractures.

29. Unstable trochanteric fractures; extramedullary or intra medullary fixation I b schipper et al, injury, int.j.care injured (2004)35, 142-151.concludes that sliding hip screw is better implant for stable trochanteric fractures.intramedullary implant is biomechanically superior for unstable trochanteric fractures

30. N K karn, G K sing, B shrestha, M P singh; management of trochanteric fracture of femur in Nepal; JBJS 2006(british) 88-b, 1347-1350

31. Ricci William M: New implant for the treatment of intertrochanteric Femur fracture; Techniques in orthopaedics special issue; high usage Articles, sep 2008, 23(3): 222/231.

32. boyd and griffin:classification and treatment of trochanteric fractures;arch surg;1949;58;853866

33. Evans EM. Treatment of trochantericfractures of the femur.J BoneJointSurg(B): 190

34. A.0 orthopaedic trauma association committee for coding and classification fracture and dislocation compendium; jorthop trauma 1996;10(1);30-35.

35. Chaurasia B.D: Human Anatomy Regional and apllied Lower limb and abdomen Pg.108109:198183) 
36. Netters Anatomy

37. GuptaRC.ConservativeTreatmentofIntertrochantericFracturesoftheFemur. Indian Journal of Orthopaedics 1974; 36(6): 229.

38. KudernaH, BohlerNandCollonDJ.TreatmentofIntertrochantericand Subtrochantericfracturesof theHipbytheEnder Method.JournalofBoneand Joint Surgery 1976; 58A: 604-611.

39. KauferK, MatthewsLS, SonstegardD, MichiganAA.Stablefixationinintertrochanteric fractures. J Bone Joint Surg 1974;56-A:89-907

40. Kyle RF, Gustilo RB and Premer RF. Analysisof 622 IntertrochantericHipFractures: A Retrospective and Prospective Study. Journal of Bone and JointSurgery 1979; 61A: 216-221. .

41. Wolfgang GL, Bryant MH, O'Neill JP. Treatment of Intertrochanteric fracture ofthe femur using Sliding screw plate fixation. ClinOrthop 1982; 163:14894.

42. DolkT.OperationonhipfracturepatientAnalysisofthetimefactor.Injury1990;21:369-392

43. Ecker ML, Joyce JJ, Kohl EJ. The treatment of trochanteric hip fractures usingcompression screw. J Bone Joint Surg 1975;57A:23-27

44. DoppeltSH.TheSlidingcompressionscrew, today'sbestanswerforstabilizationofIntertrochanterichipfractures.OrthopClinNorthAm1980;1 $1: 507-523$

45. Dynamic hip screw in fractures of the proximal femur, Gulzar Ahmed Hagroo Et al, Vol. 28, No.2, May 1994, Indian journal of orthopaedics

46. Results of intertrochanteric femur fractures treated with a 135-degree sliding screw with a two - hole side plate, Bolhofner Et al, journal of orthopaedic trauma, jan 1999, 13(1): 5-8

47. Sliding hip screw fixation of trochanteric hip fractures: Outcome of 1024 procedures, N.Chirodian Et al, Injury, Int. J. Care injured (2005) 36, 793-800

48. Management of trochanteric fractures, ChArun Kumar Singh, Et al, Indian journal of orthopaedics, April 2006, Volume: Number 2: P. 100-102

49. Management of intertrochanteric fractures by Dynamic hip screw/ Dynamic Martin Screw, Anil Kumar Mishra, J.Orthopaedics 2007; 4(2) e40

50. Harris hip score; Harris WH;(modified) JBJS 1969; 51:1.

51. Hornby R et al. Operative or Conservative Treatment for Trochanteric Fractures of the Femur. Journal of Bone and Joint Surgery 1989; 71B: 619-623.

\section{AUTHORS:}

1. G. Kishore Roy

2. Muralidhar Bandi

\section{PARTICULARS OF CONTRIBUTORS:}

1. Professor and HOD, Department of Orthopaedics, ASRAM Medical College Hospital.

2. Resident, Department of Orthopaedics, ASRAM Medical College Hospital.

\section{NAME ADDRESS EMAIL ID OF THE} CORRESPONDING AUTHOR:

Dr.G. Kishore Roy, Professor and HOD, ASRAM Medical College, Malkapuram, Eluru - 534004, West Godavari, Andhra Pradesh, India. Email-kishoreroy@yahoo.com

Date of Submission: 20/11/2013.

Date of Peer Review: 23/11/2013.

Date of Acceptance: 19/12/2013.

Date of Publishing: 08/01/2014 